\section{Quality assurance in learning material development at OUM}

\section{QA in learning material development}

\author{
Nazrai Ahmad Zabidi, Tai Kwan Woo, P. Rajesh Kumar, \\ Mansor Fadzil and Syarifah Hidayatul Syed Husain \\ Open University Malaysia, Kuala Lumpur, Malaysia
}

\begin{abstract}
Purpose - The purpose of this paper is to discuss the stages involved in the module development process at the Open University Malaysia (OUM), to make them "print ready," and how this has evolved over the years with various quality assurance $(\mathrm{QA})$ mechanisms in place.

Design/methodology/approach - The paper builds upon the 12 quality control checks in the various stages of module development from pre-development to actual development and finally to post-development process. This is in line with the QA continuous improvement process of PDCA or Plan, Do, Check and Act. Findings - Change, through the fine-tuning of QA processes and open door communication, is the key toward achieving quality modules, and hence meeting learners' expectations.

Research limitations/implications - This paper highlights the experiences of only the Centre for Instructional Design and Technology, OUM in the development of quality learning material for the Open and Distance Learning (ODL) learners.

Originality/value - This paper outlines the step-by-step process in module development, from print to print-ready material, to assist the ODL universities in their mission to provide quality learning material to learners.
\end{abstract}

Keywords Customer satisfaction, Quality assurance, Learning material

Paper type General review

\section{Introduction}

The success and effectiveness of the distance education system "depends heavily on the study material, particularly in the form of printed course material" (Jayaram and Dorababu, 2015). Quality in the Open and Distance Learning (ODL) institutions and their programs are often judged in relation to study material because "student learning is at the center of the ODL experience" (Kirkpatrick, 2005; Hashim, 1999). These are the pivots on which the whole learning pedagogy revolves.

ODL learners in Malaysia are also very concerned about the quality of learning material. This was borne out in a recent survey conducted among post-graduate learners in the Open University Malaysia (OUM) in which "good quality modules or study guides" was listed as one of the five items that were important to the learners (Abdol Latif et al., 2015). The survey concluded that if the course contents, among others, are positively addressed, the learners are likely to continue studying at the OUM and attain their educational goals. At the end of the day, the ODL learners aspire to achieve three main outputs, namely, "gaining new knowledge, acquiring new skills and most importantly obtaining higher qualifications" which they regard as necessary for their social and economic progress (Idrus, 2006).

Historically, quality assurance (QA) first gained prominence in the fields of engineering and manufacturing, as a means of ensuring that quality products are made. The quality gurus have provided a number of definitions of quality, such as conformance to customers'

(C) Nazrai Ahmad Zabidi, Tai Kwan Woo, P. Rajesh Kumar, Mansor Fadzil and Syarifah Hidayatul Syed Husain. Published in the Asian Association of Open Universities Journal. Published by Emerald Publishing Limited. This article is published under the Creative Commons Attribution (CC BY 4.0) licence. Anyone may reproduce, distribute, translate and create derivative works of this article (for both commercial and non-commercial purposes), subject to full attribution to the original publication and authors. The full terms of this licence may be seen at http://creativecommons.org/licences/by/4.0/legalcode
Received 27 January 2017 Revised 19 April 2017 28 April 2017 Accepted 2 May 2017 
AAOUJ

12,1

requirements (Crosby, 1979) and fitness for purpose or use (Juran and Godfrey, 1999). Deming, on the other hand, pointed out that customer's definition of quality is "the only one that matters" (Deming, 1982). Hence, QA and quality control (QC) are part and parcel of attaining quality. Moreover, QA is "a broad concept that focuses on the entire quality system" and includes quality objectives, whereas QC looks at the micro level and focuses on the process of producing the products (ASQ Statistics Division, 1983). In short, QC can also be viewed as a subset of QA (Eriksson, 2016).

From the perspective of ODL, QA should cover a wide range or areas including curriculum design, content and delivery, and the teaching and learning process (Pitsoe and Maila, 2014). In this paper, we will explain and illustrate how the Centre for Instructional Design and Technology (CiDT) at the OUM implements QA in the print module development at various stages. We will also touch on the quality management system (QMS) established in CiDT since it was first awarded the MS ISO 9002:2008 certification in 2005. Finally, we will look into the satisfaction level of learners with OUM's learning material.

\section{QA in ODL}

Around the world, the burgeoning demand for ODL institutions to provide opportunities to learners to pursue higher education has shifted the attention of stakeholders and interested parties to the importance of quality. In light of the increasing competition with conventional universities, the ODL institutions need to offer quality courses and modules that satisfy learners and make them feel there is value for money and the education is a good investment; this in turn ensures that the ODL institutions can continuously "sell and survive" (Koul, 2010) and, at the same time, overall improvements in quality in addition to openness and transparency become the key drivers of "competition and collaboration in education and research" (Anderson, 2008; Ossiannilsson and Creelman, 2012).

With respect to higher education, QA has been defined as the "systematic management and assessment procedures adopted by higher education institutions and systems in order to monitor performance against objectives and to ensure achievement of quality outputs and quality improvements" (Harman, 2000). Alternatively, QA has been defined as "a set of activities or procedures that an organization undertakes to ensure that standards are specified and reached consistently for a product or service" (Robinson, 1995) as well as a set of activities that provide "value for money and transformation capabilities" to ODL students (Gandhe, 2010). In a nutshell, QA "helps disseminate best practices, with the prime objective of leading to overall improvement of higher education systems" (Belawati and Zuhairi, 2007).

In addition, an ODL institution can build its good name by having "a systematic and consistent QA system" resulting in a positive impact on its stakeholders, e.g. more satisfied students, more competent personnel and better public image; meanwhile, students too will benefit as they achieve "enhanced learning outcomes from quality instruction, learning materials and interactions with the institution and its staff" (Kirkpatrick, 2005). Hence, providers need to emphasize quality in various aspects such as products, processes, production and delivery systems (Commonwealth of Learning, 1997). For educational institutions, including the ODL, ISO 9000 assures quality in terms of programs and courses, meeting the intended goals and needs of the users, in particular, the learners (Koul, 2010).

\section{QA related to tertiary education in Malaysia}

In general, there are two best-practice QA and accreditation agencies in Malaysia, which are Malaysian Qualifications Agency (MQA) and Scientific and Industrial Research Institute of Malaysia (SIRIM). 
MQA was "established under the Malaysian Qualifications Agency Act 2007 by the Ministry of Higher Education" (Malaysian Qualifications Agency, 2009) and is responsible for QA of higher education for both the public and the private sectors in Malaysia. One of the initiatives of MQA is carrying out a rating exercise of Malaysian Higher Education Institutions at the undergraduate level, known as SETARA. In 2011, the ODL category was introduced for the first time to rate the quality of teaching and learning at the ODL institutions in the country, "with 23 criteria and 52 indicators for ODL institutions which include process dimensions such as quality delivery and pedagogy" (Mahsood and Chenicheri, 2016).

MS ISO 9001 is one of the Malaysian Standards developed by SIRIM, whereas ISO 9001 is an international standard that many companies use to ensure that their QA system is established and effective. ISO 9001 demonstrates "an organization's ability to maintain quality in products and services, meeting the requirements of customers and regulations" (Scientific and Industrial Research Institute of Malaysia, 2016).

QA for the ODL programs and institutions is one of the main concerns among institutions and stakeholders today. This is in line with the Malaysian Education Blueprint (2015-2025) which aspires to see lifelong learning as a way of life for all Malaysians. The blueprint further stipulates that "there will be high quality formal, non-formal, and informal programs in a wide range of disciplines and topics to support both professional and personal development" (Ministry of Education, 2013).

\section{A brief background of the OUM and the CiDT}

OUM has had a long history in developing study materials for its distance learners. OUM was the first ODL institution in Malaysia and commenced operations in 2001, beginning with the face-to-face mode of learning aided with printed modules and a learning management system platform. Since its inception, the University has been at the forefront championing an accessible, affordable and flexible approach to learning via the ODL mode. OUM has also been highly ranked in the SETARA ODL category with an excellent Tier 5 rating - a testament to the overall quality of the university (Malaysian Qualifications Agency, 2013).

The university has given working adults in Malaysia the opportunity to pursue higher education anytime and anywhere via the ODL mode. Over the years, the university has grown from strength to strength and this is evident from the fact that presently the OUM has 154,000 cumulative learners, 1,000 international learners and 70,000 graduates. The university also employs about 8,000 part-time tutors, 100 full-time faculty members and 500 support staff. Unlike the other ODL providers in the world, the OUM is unique in that it is owned by a consortium of 11 public universities. These public universities have been generous in lending their prestige and expertise in the various fields; this collaboration has added value to the wide range of programs provided by the OUM. Presently, the University practices a blended pedagogy which comprises self-managed learning, face-to-face tutorials and online learning. This pedagogy is dependent on print-ready self-instructional learning materials, commonly known as "modules."

At the OUM, the CiDT is primarily responsible for the development of learner-friendly and specially constructed modules (Open University Malaysia, 2008). As of May 2016, the CiDT has developed 1,392 print-ready modules, 366 study guides, 865 hypertext markup language (HTML) modules and 181 video lectures. These HTML-based modules help to enrich the learning experience with colorful graphics, interactive activities and exercises, embedded audio and video files as well as links to other online learning resources. Since the HTML modules and video lectures are sourced from printed modules, it is vital for the module development process to undergo a stringent QA process. 
AAOUJ

12,1

On October 2005, the CiDT was among the four learner support service centers in the OUM to be awarded the prestigious MS ISO 9001:2000 certification (Ali and Fadzil, 2013). The growing number of learning materials made it vital for the center to embrace a QA culture. Moreover, the center is the largest unit in the university comprising more than 60 staff with expertise from various disciplines.

\section{The importance of quality print modules in the OUM}

When the CiDT opted to pursue the MS ISO 9001:2000 certification, the scope was limited to printed learning materials for programs offered by the OUM. Currently, there are five core activity procedures for print modules:

(1) acceptance, selection and appointment of subject matter experts (SMEs);

(2) instructional and graphic design;

(3) desktop publishing;

(4) management of module writing and moderating workshop; and

(5) measurement of customer satisfaction.

Ideally, quality learning materials in an ODL setting must be "simple to interact with and should be understood by learners," so much so that the materials should be self-explanatory, requiring minimal or even no assistance from tutors (Adegoke and Oni, 2015). It has been shown that learners who scored poorly on reading tests were more likely to drop out before completing their courses (Macdonald-Ross and Scott, 1996). If learners are unable to understand the module, they may underperform in their exams, lag behind in their studies, become demoralized and eventually contribute to the high attrition rate of learners at the ODL institution. In fact, the factors for the high attrition rate among ODL learners include "study material in tough or difficult language and delay or non-receipt of study material" (Kumari, 2012). Meeting deadlines is also very important, as failure to achieve the set deadlines can affect other subsequent processes and lead to "devastating consequences" (Belawati and Zuhairi, 2007).

In addition to this, QA is very much output-outcome driven. Initially, the OUM identified three outputs of QA in the ODL for the University, namely, "graduates with new knowledge, graduates with new skills and graduates with new qualifications" (Idrus, 2006). New skills here include language skills in the English language and relevant skills, such as skills in Finance that will allow learners to perform finance-related calculations. As the learners are mostly working adults, the outcomes among others include job promotion, respect in the community and the pursuit of new interest. Additional relevant skills acquired after graduating from the OUM will be part of the additional list of accomplishments to show value that will be useful for "moving up the corporate ladder" (Zhang, 2014).

Hence, the accuracy of the content in learning material is crucial. Information must be up-to-date and new changes must be taken into consideration as these will "ensure the appropriateness and quality of the learning materials" (De Fazio et al., 2012). Therefore, there should be zero-tolerance for errors such as grammatical error, factual error or mistakes in formula or calculations in the learning material. Learning material which is difficult to understand will contribute to high attrition (Kumari, 2012), whilst "inaccurate and outdated learning material" will not make the learners achieve the desired outcomes (Idrus, 2006).

All five of the SOPs were designed to ensure that QCs are in place so that the print-ready modules are of benchmark standards that satisfy the learners' expectations. Since the CiDT was first awarded the MS ISO 9001:2000 certification in 2005, the center has undergone a number of quality audits which saw corrective and preventive actions (CAPAs) implemented by way of PDCA or Plan, Do, Check and Act. This requires mastering each 
process, knowing how to govern it in a way that enhances communication, transparency and accountability. Understanding and analyzing the root cause of problems is imperative to prevent the same problems from recurring (Olzak, 2008). This calls for stringent QC measures which will be discussed in the next section.

\section{The QA process for print module development}

At the CiDT, there are three stages involved in the QA of print module development. These include the pre-development, actual development and post-development stages. Figure 1 shows all the stages and the respective QC measures that will be explained in the following subsections.

\section{QA at pre-development stage}

In this stage, there are four $\mathrm{QC}$ measures in place to ensure that the OUM modules are of benchmark quality.

The first QA check at this stage is the selection of module writers. This has always been stringently done. The modules are written by writers who are (SMEs) nominated by faculty and vetted by the CiDT to ensure that they have the right academic credentials and relevant work experience in their respective fields. Following ISO requirements, the records of all writers are well-maintained and documented.

The second QA check is the module writing and moderating workshop. Upon appointment by the CiDT, the writers and moderators are required to attend a module writing and moderating workshop where they are briefed on general principles of instructional design, house style and editorial format, timelines and expectations, graphics, referencing and citation, as well as the rubrics for evaluation and payment. Attendance at this workshop is a pre-requisite for module development at the OUM, as everything begins with the writers and moderators who must be clear what the requirements and expectations are. Furthermore, writing modules for ODL learners is "an art in itself" because its interactive styles and techniques are distinct from conventional textbook writing (Rahman, 2006; Hashim, 1999).

At this workshop, the writers and moderators are also introduced to the module development team from both faculty and the CiDT so that they feel a sense of collegiality and esprit de corps for the journey that lies ahead. The development of learning materials by a team of SMEs, academic moderators, module writers, tutors and consultants is part of the

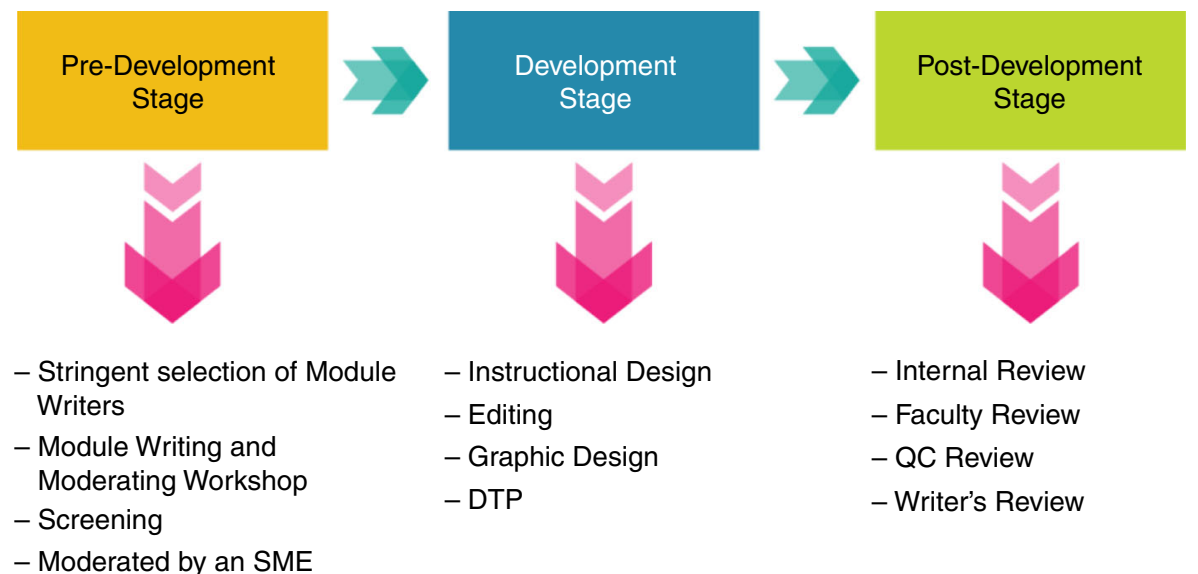

QA in learning material development 政 
AAOUJ

12,1

OUM strategy of giving priority to learners and providing them with quality services and products (Kirkpatrick, 2005).

The third quality check is enforced once the module content comes in. This comes in the form of a plagiarism/similarity check via Turnitin ${ }^{\mathcal{O}}$ software to ascertain whether the content submitted by the writer is original and not taken from other sources. Turnitin ${ }^{\mathcal{O}}$ is a popular web-based plagiarism detection software used in Malaysia and abroad that is "able to match the work submitted by a module writer against works done by other writers from its huge database repository" (Rogers et al., 2009). If the content is found to be highly plagiarized, it will then be returned to the writer for amendment.

Besides plagiarism, the raw content will undergo a screening process conducted by the instructional designers (IDs). Detecting plagiarism is only one aspect of screening. Furthermore, the IDs will ensure that learning outcomes incorporate the Blooms Taxonomy (a progression from lower order to higher order thinking skills) and the desired outcomes. This allows the learning outcomes to be stated in "measurable behavioral or operational verbs" for the learner to monitor his or her own progress (Koul, 2010). Behavioral verbs have two distinct advantages. First, we can use them to "devise activities that make the student an active participant in his or her learning" and second, "the verbs may be used to help to translate the course goals and objectives into situations that are more concrete to the learners and others" (University of North Carolina at Charlotte, 2016). At this stage, contents are checked against the table of contents (TOC) to ensure that they are in accordance with the TOC given by the faculties. References are standardized according to the APA style used in the OUM. A ten-item checklist identifying the elements that need to be present in the content is used as a tool by the IDs throughout the screening procedure. If there are any issues such as plagiarism, improper learning outcomes or improper in-text citation and references, the content will be immediately sent back to the writer for amendments.

Only after these three $\mathrm{QC}$ checks have been carried out is the content forwarded to a moderator, an SME in the same field who is nominated by faculty and appointed by the CiDT. The role of the moderator is to ensure that what has been written follows the specifications spelled out by faculty. So, in this sense, the content is vetted for breadth and depth in terms of scope and coverage by a second expert in the field. Moderators are selected based on specific criteria, such as being of similar, or higher, academic standing as the writer. Professionalism is a necessary ingredient in the production of quality learning material (UT, 2002); hence, the proper selection of competent writers and moderators is taken seriously at the CiDT. If the moderator feels the content is lacking or inappropriate in any way, the writer is obliged to make the necessary amendments based on the moderator's feedback.

\section{QA at the actual development stage}

This stage sees the involvement of IDs, editors, graphic designers (GDs) and desktop publishers (DTPs). At the CiDT, there are currently 11 IDs, 5 editors, 12 GDs and 10 DTPs who have expertise in different disciplines. In addition to these different units, there are four dedicated Project Coordinators or PCs for each faculty at the CiDT, and they are responsible for liaising with both internal and external parties in module development for their respective faculties and in coordinating the movement of modules to completion. The PCs play a critical role in the overall coordination of module development as they track the progress of each and every module as early as the pre-development stage, to ensure the modules are delivered within the stipulated timelines given to the writers in the appointment letter. The whole module development process can be likened to "the procedures in an assembly line" and any delay at the preliminary stage can have a devastating outcome on subsequent downstream stages (Belawati and Zuhairi, 2007). 
At this stage, the module content is first assigned to an ID who will develop the module based on the quad alignment model shown in Figure 2. All the four components of the model, namely, body of content, learning outcomes, assessment tasks and learning activities are explained and illustrated during the module writing and moderating workshop. Besides understanding each component, it is vital for all the components to be aligned with each other, that is "support and be directly relevant to each other," thereby helping the learners to easily understand the modules (Fink, 2007).

Hence, the IDs and the writer have to work closely to ensure that every topic is "quad-aligned" so that the learners will find the module easy to comprehend. Apart from writers, the relevant faculty members who are known as program coordinators also provide academic input to beef up the content and ensure that the learning outcomes in each topic are elaborated adequately.

The content in a module must be designed in a systematic way to facilitate learning without regular supervision of a tutor. The content must also be interactive with "an element of guided didactic conversation that can create warmth, closeness and two-way communication between learner and materials or between learner and the module writer" (Holmberg, 1977). Toward this end, IDs have specific roles to play in ensuring that "the learning outcomes are clear to the learner, content is arranged in the proper sequence, there are adequate activities, diagrams and illustrations to aid learners and also assignments to regulate learners' progress" (Koul, 2010). In some cases, the ID may suggest to the writer parts of the content that should be revised or rewritten to better meet the learning needs of learners. For instance, a well-written introduction to a topic can grab a learner's attention and arouse his/her interest to continue reading the module.

Among the activities that can be found in the OUM modules are self-checks and self-tests, i.e. self-assessments; for post-graduate learners, the modules include several case studies as well. These are designed to make learning interesting, interactive, meaningful and collaborative. Some of the activities also encourage learners to communicate with their peers through the e-forum and post their answers on myINSPIRE, the learning management system of the OUM.

The content is then edited to improve the language, flow and readability of the content without compromising on the original meaning. The upshot of this is that the content becomes more readable, self-explanatory and easier for the learner to understand (i.e. written in a user-friendly language), requiring minimal tutor guidance. The editor also ensures that the content meets the in-house style standards and verifies headings, statistics and data in graphs and figures. After the editing process, the IDs then work closely with GDs to visualize and incorporate graphic elements to enhance the overall visual presentation of the content. A picture is said to be worth a thousand words; thus, the GDs play an important role to ensure the graphics and diagrams can make the module content more coherent to the learners. Finally, the content is sent to the DTPs for layout in the OUM in-house style to maintain the OUM identity. The DTPs also combine text,

\section{QA in learning material development}

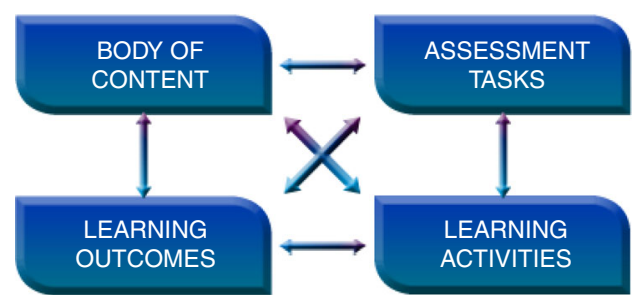

Source: Phillips (2006)

Figure 2.

The quad alignment model 
AAOUJ

12,1

numerical data, photographs, charts and other graphic elements to produce print-ready modules in the PDF format.

Throughout this stage, there will be an open door communication and mutual consultation among all relevant parties, both within and outside the CiDT. Every staff must also be competent in his or her respective field. A high level of professionalism (UT, 2002) is required in a quality work culture to ensure the process is done correctly and within the set deadline.

\section{QA at the post-development stage}

Once the actual development stage has been completed, the ninth QC check kicks in as a hard copy of the module is printed out and sent to the ID for a process called internal review (IR), to ensure that everything has been put together correctly. Here, the IDs will perform a final review of the content to verify that the learning outcomes, content, learning activities and assessments are in sync with each other and to make sure that the module is error free.

After amendments based on the IR have been done, the module is sent to faculty for review. At this stage, the program coordinator or the vice-dean of learning materials will vet the module prior to sign-off for print or upload. Amendments may still be requested at this stage.

Once a module has been signed off, a dedicated QC team at the CiDT vets through the final copy once more before it is printed or uploaded. This QC team comprises the director, academics and senior staff at the CiDT who have strong language skills and are well-versed in module development. To standardize the QC process, the CiDT has come up with a checklist to be used by the team. Some of the elements listed in the checklist include checking and correcting the following:

(1) the credit page for the latest version;

(2) language errors;

(3) figures, tables, activities and self-check questions in terms of suitability and relevance; and

(4) alignment and indentation.

After this stage, a soft copy of the final module is sent back to the writer for feedback, on the understanding that if there are no amendments from the writer within a week, the module is deemed approved and ready for print or upload.

According to the quality objectives of the CiDT, the process development must be completed within four months of receiving the content from the moderator. As mentioned earlier, deadlines must be met in order to prevent delay of subsequent activities such as timely delivery of modules to learners.

\section{From print to $E$}

With effect from May 2016, the OUM no longer produces print modules. This is in line with global trends and initiatives to completely migrate the learning content toward E. Instead, e-modules are made available on the learning management system of the OUM known as myINSPIRE for learners who wish to download them in PDF format. Learners can either download the entire module or download each topic seperately, which has been made possible after the process of chunking. Meanwhile, bookmarking allows learners to navigate to a particular topic or subtopic within the module by clicking on the TOC.

There is also a module feedback mechanism in place on myINSPIRE, whereby learners can convey suggestions to the CiDT - this feedback is then channeled back to the faculty, who may request for module enhancement, in line with the PDCA model. 
A module which is deemed stable is categorized as Red Spine. As a general rule of thumb, a Red Spine module is used for about three years before it is again looked into, in keeping with the philosophy of continuous improvement. Knowledge is the "currency a university deals in," and this knowledge is constantly upgraded to remain current and abreast of changes (De Fazio et al., 2012). The role of the CiDT is to assist the university in this task.

The entire module development process is presented in Figure 3.

\section{Customer feedback}

The commitment from the OUM top management throughout the years has been a critical factor in driving the quality culture at the CiDT and the organization as a whole. In line with this commitment to quality, the CiDT conducts a customer satisfaction survey at the end of every academic cycle to gauge feedback regarding the learning material developed and used in that cycle. The benchmark was set at 80 percent by the CiDT management.

Consequently, as shown in Table I, customer satisfaction surveys have shown the satisfaction results to consistently hover above the benchmark of 80 percent for the past four years. Meeting or exceeding 80 percent of satisfaction for each production cycle is another quality objective of the CiDT.

Quality learning can be said to be achieved when the feedback indicates that the outputs and outcomes of the modules are satisfactory (Idrus, 2006). Even if the benchmark set is not at 100 percent, it does not mean that there is a lack of quality as "quality assurance does not expect perfection"; rather there is an expectation from the CiDT to commit toward improvement (Pitsoe and Maila, 2014). The feedback gained from the survey as well as other feedback mechanisms will provide useful input toward PDCA and further enhance the print module development process.

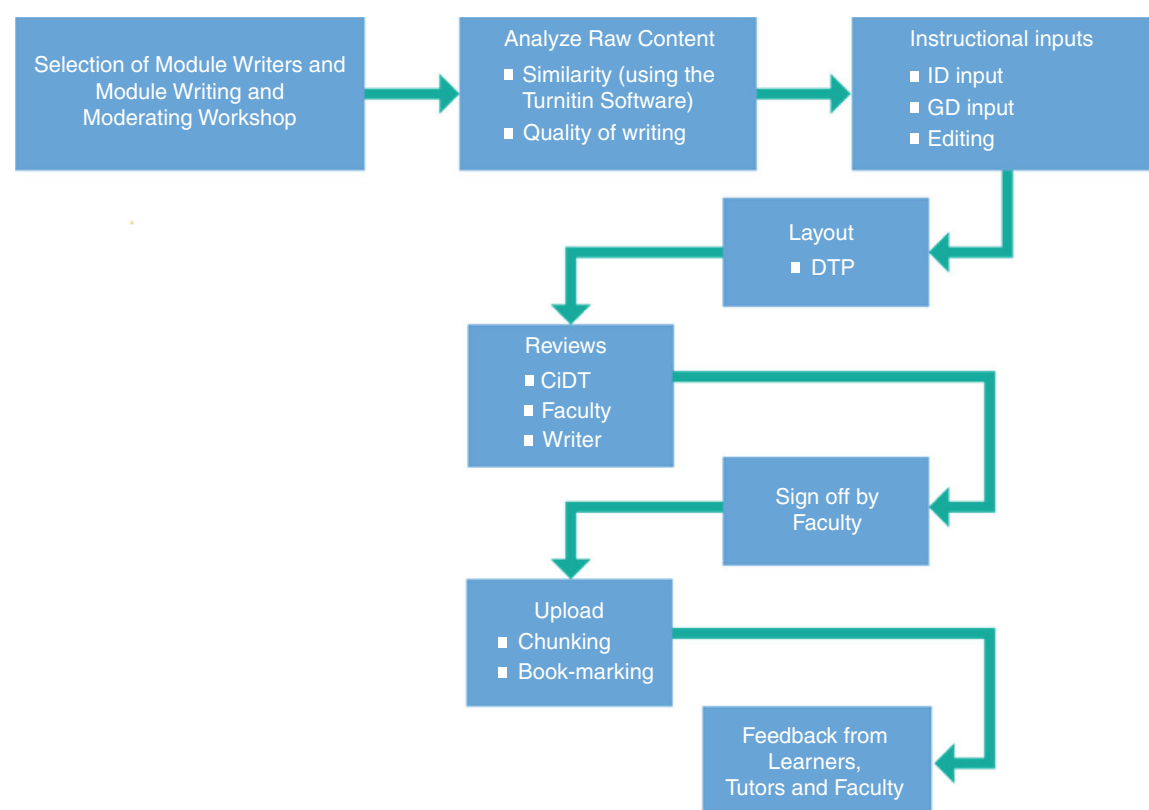

QA in learning material development 
AAOUJ
12,1

AAOUJ
12,1

78

Table I.

Percentage level of customer satisfaction
Semester

Customer satisfaction (\%)

September 2012

73.5

January 2013

May 2013

September 2013

January 2014

May 2014

September 2014

January 2015

May 2015

September 2015

January 2016

Note: Module feedback form from September 2012 to January 2016 semester cycle
82.8

83.5

83.9

81.8

80.7

86.0

87.1

89.55

71.80

83.2

\section{Conclusion}

The increase in customer satisfaction shown in Table I demonstrates the positive impact that the QA culture has on the print module development process at the OUM. CiDT has been adopting a stringent auditing process yearly, since 2005, and the continuous improvement efforts have produced a desirable result. These audits include self-audit, internal audit and, finally, quality audit by SIRIM. The QA process for print module development is very clear in defining what the standards of achievement are, including documented procedures for each process.

The QMS in the CiDT is crucial to ensure the continuity of the quality work culture. The various procedures and work instructions that are in place set out a number of tools to facilitate the module development process. Checklists are available in most processes such as screening, conducting module writing and moderating workshops and also during the actual development stage. If followed correctly, the staff will not leave out any important work instruction and the processes can be executed smoothly and effectively.

Besides checklists, the CiDT has a number of feedback processes in place. Clause 8 of the MS ISO 9001:2015 requires the QMS to establish proper measurement, analysis and improvement (Department of Standards Malaysia, 2016). Implementing quality programs such as ISO certification encourage higher education institutions in Malaysia to collect data, which will "enable them to measure progress in key areas and establish benchmarks" (Sohail et al., 2003). The screening checklist for instance also doubles up as a feedback mechanism as it allows IDs to evaluate whether the writers fulfill the requirement set by the CiDT. After the module writing and moderating workshop, the participants consisting of module writers and moderators are given a questionnaire to gauge their level of satisfaction and also to gain input from the participants regarding the workshop. The customer satisfaction survey shown earlier in Table I is also important to gain vital feedback from the ultimate customer - the learners. In addition to these, there are frequent meetings with the faculties to discuss and thrash out issues pertaining to progress in developing the learning materials. Apart from learners being satisfied with the modules, the respective faculty or in this case program coordinator from the faculty, should also be satisfied with the outcome of the modules (Idrus, 2006).

As a result, many potentially serious issues that can lead to non-conformance have been detected and successfully resolved through CAPA. The initiatives introduced after the ISO certification include the screening process, the use of Turnitin software and the setting up of a QC team. Several tools were added to the processes from the pre-ISO stage, such as providing a step-by-step guide to participants for the module writing and moderating workshop and detailed work instructions for all staff. These have led to continuous improvement by reducing wastage in terms of redundancy and having a clearer workflow. 
The road ahead is full of challenges as the OUM migrates to more modules that are fully online because the modules must be of good quality to meet learners' needs and expectations. Migration also indicates that new QC measures must be established to ensure that the fully online modules meet or exceed the learners' expectations. We further plan to study the impact that the migration to fully online modules has had on the customer's satisfaction index, and data are currently being gathered for this purpose. The risks are high as the global education platform becomes increasingly competitive and learners more discerning. But at the same time, opportunities abound for the CiDT to assist the University in its mission to provide quality learning materials and make education accessible to all.

\section{QA in learning material development}

\section{References}

Abdol Latif, L., Bahroom, R. and Khalil, M.A.K.M. (2015), "Prioritizing services and facilities in a higher education institution: importance-satisfaction quadrant and gap analyses", Proceedings of 29th AAOU 2015 Conference: New Frontiers in ODL, OUM, Kuala Lumpur, p. 676, available at: http://library.oum.edu.my/oumlib/announcements/19-01-2016/proceedings-of-asian-associationof-open-universities-aaou-conference-2015 (accessed August 12, 2016).

Adegoke, B. and Oni, A. (Eds) (2015), "Teacher education in open and distance learning universities in Africa", Teacher Education System in Africa in the Digital Era, Codesria, Dakar, p. 56, available at: file:///C:/Users/User/Downloads/05._onuka\%20(4).pdf (accessed August 16, 2016).

Ali, A. and Fadzil, M. (2013), "Open University Malaysia”, in Jung, I., Wong, T.M. and Belawati, T. (Eds), Quality Assurance in Distance Education and E-learning: Challenges and Solutions from Asia, Sage Publications, New Delhi, p. 263.

Anderson, T. (Ed.) (2008), The Theory and Practice of Online Learning, Athabasca University Press, Edmonton.

ASQ Statistics Division (1983), "Glossary \& tables for statistical quality control”, available at: www. shsu.edu/ mgt_ves/mgt481/lesson1/lesson1.htm (accessed December 31, 2015).

Belawati, T. and Zuhairi, A. (2007), "The practice of a quality assurance system in open and distance learning: a case study at Universitas Terbuka Indonesia (the Indonesia Open University)", International Review of Research in Open and Distance Learning, Vol. 8 No. 1, pp. 2-4, available at: www.irrodl.org/index.php/irrod1/ article /view/340/774 (accessed August 15, 2016).

Commonwealth of Learning (1997), "Planning and management of distance education: Commonwealth of Learning", Commonwealth of Learning and International Extension College, London.

Crosby, P.B. (1979), Quality is Free: The Art of Making Quality Certain, New American Library, New York, NY, p. 17.

De Fazio, T., Ketonen, J. and Crock, M. (2012), "Quality assurance in a consortium: open universities Australia", in Jung, I. and Latchem, C. (Eds), Quality Assurance and Accreditation in Distance Education and e-Learning: Models, Policies and Research, Routledge, New York, NY, pp. 124-129.

Deming, W.E. (1982), Out of the Crisis, MIT Press, Cambridge, MA.

Department of Standards Malaysia (2016), "MS ISO 9001:2015 - quality management systems", available at: www.jsm.gov.my/ms-iso-9001\#.WHLe71N974Y (accessed January 2, 2017).

Eriksson, U. (2016), "Quality assurance vs quality control: know the difference", available at: http://reqtest. com/testing-blog/quality-assurance-vs-quality-control-differences/ (accessed December 29, 2016).

Fink, L.D. (2007), "Teaching tips index”, available at: http://honolulu.hawaii.edu/ intranet/ committees/ Fac DevCom/guidebk/teachtip/active.htm (accessed August 5, 2016).

Gandhe, S.K. (2010), "Quality assurance in open and distance learning in India”, Open Praxis, Vol. 4 No. 1, pp. 26-32.

Harman, G. (2000), Quality Assurance in Higher Education, Ministry of University Affairs \& UNESCO PROAP, Bangkok. 
AAOUJ

12,1

Hashim, Y. (1999), “Are instructional design elements being used in module writing?”, British Journal of Educational Technology, Vol. 30 No. 4, pp. 342-356.

Holmberg, B. (1977), Distance Education: A Survey and Bibliography, Kogan Page, London.

Idrus, N. (2006), "Quality assurance in ODL", Proceedings of the 6th SEAAIR Conference, OUM, Kuala Lumpur, pp. 284-291.

Jayaram, K. and Dorababu, K.K. (2015), "Self learning materials in distance education system", International Journal of Current Research, Vol. 7 No. 10, pp. 21929-21934.

Juran, J.M. and Godfrey, A.B. (Eds) (1999), Quality Control Handbook, 5th ed., McGraw-Hill, New York, NY.

Kirkpatrick, D. (2005) Quality Assurance in open and Distance Learning: A Topical, Start-up Guide to Distance Educational Practice and Delivery, Commonwealth of Learning, Vancouver, available at: http://oasis.col.org/bitstream/handle/11599/103/KS2005_QA.pdf?sequence=1\&isAllowed=y (accessed January 3, 2017).

Koul, B.N. (2010), Quality Assurance in ODL Institutions, Commonwealth Educational Media Centre for Asia, New Delhi.

Kumari, S. (2012), "Factors affecting students' retention and attrition in the open and distance learning system”, Indian Journal of Open Learning, Vol. 21 No. 1, pp. 19-40.

Macdonald-Ross, M. and Scott, B. (1996), "The readability of OU foundation courses”, Technical Report No. 5, Text \& readers programme, The Open University, Milton-Keynes.

Mahsood, S. and Chenicheri, S.N. (Eds) (2016), A Global Perspective on Higher Education, Chandos, Cambridge, pp. 145-146.

Malaysian Qualifications Agency (2009), "Quality assuring higher education in Malaysia: the Malaysia Qualifications Agency (MQA)", available at: www.mqa.gov.my/aqaaiw/Country\%20Report/ Malaysia/2\%20\%20QUALITY\%20ASSURING\%20Final.ppt (accessed August 7, 2016).

Malaysian Qualifications Agency (2013), "The 2013 rating for higher education institutions in Malaysia”, available at: www.mqa.gov.my/PortalMQAv3/SETARA13/SETARA $\% 20113 \% 20$ Result.pdf (accessed January 3, 2017).

Ministry of Education (2013), "Malaysian education blueprint 2013-2015 (preschool to post-secondary education)", available at: www.moe.gov.my/cms/upload_files/articlefile/2013/articlefile_file_ 003108.pdf (accessed August 7, 2016).

Olzak, T. (2008), "Prevent recurring problems with root cause analysis", available at: www. techrepublic.com/blog/it-security/prevent-recurring-problems-with-root-cause-analysis/ (accessed August 16, 2016).

Open University Malaysia (2008), Nurturing Excellence, Open University Malaysia, Kuala Lumpur, p. 42.

Ossiannilsson, E. and Creelman, A. (2012), "From proprietary to personalized higher education - how OER takes universities outside the comfort zone", Journal of e-Learning and Knowledge Society, Vol. 8 No. 1, pp. 10-22.

Phillips (2006), "Guidelines for writing interactive learning modules" (unpublished).

Pitsoe, V.J. and Maila, M.W. (2014), "Quality and quality assurance in open distance learning (ODL) discourse: trends, challenges and perspectives", Anthropologist, Vol. 18 No. 1, pp. 251-258.

Rahman, M.H. (2006), "Developing course materials for open and distance learning: BOU perspective", Turkish Online Journal of Distance Education, Vol. 7 No. 4, pp. 55-60.

Robinson, B. (1995), "The management of quality in open and distance learning", Eighth Annual Conference of the Asian Association of Open Universities, Structure and Management of Open Learning Systems. Indira Gandhi National Open University, Vol. 1, New Delhi, p. 97.

Rogers, P.L., Berg, G.A, Boettcher, J.V., Howard, C., Justice, L. and Schenk, K.D. (Eds) (2009), Encyclopedia of Distance Learning, 2nd ed., Information Science Reference, Hershey, PA, p. 608.

Scientific and Industrial Research Institute of Malaysia (2016), "ISO 9001 quality management system certification scheme", available at: www.sirim-qas.com.my/index.php?option=com_content\& task=view\&id=36\&Itemid= 46 (accessed August 21, 2016). 
Sohail, M.S., Rajadurai, J. and Abdul Rahman, N.A. (2003), "Managing quality in higher education: a Malaysian case study", International Journal of Educational Management, Vol. 17 No. 4, pp. 141-146.

University of North Carolina at Charlotte (2016), Action Verbs with Examples, The Center for Teaching and Learning UNC Charlotte, Charlotte, available at: http://teaching.uncc.edu/ learning-resources/articles-books/best-practice/goals-objectives/action-verbs (accessed December 30, 2016).

UT (2002), Sistem Jaminan Kualitas Universitas Terbuka (Quality Assurance System of Universitas

QA in learning material development

\section{Corresponding author}

Nazrai Ahmad Zabidi can be contacted at: nazrai@oum.edu.my

For instructions on how to order reprints of this article, please visit our website: 